\title{
Análise comparativa das metodologias de avaliação das agências de fomento internacionais BID e BIRD em financiamentos de projetos sociais no Brasil
}

\author{
Michelle C. Stephanou*
}

Na história recente brasileira, o movimento de transformação do Estado, em termos econômicos, sociais e políticos, tornou-se um desafio para a consolidação da democracia, depois de um longo período militar. As funções do Estado se ampliaram, em termos sociais, havendo uma reorientação da política social, como uma dimensão central do modelo das relações entre Estado, Economia e Sociedade. Estas transformações têm gerado demandas direcionadas à democratização de políticas públicas mais eficazes em relação às questões sociais.

\footnotetext{
Mestre em Ciências Sociais (Pucrs), professora do curso de Direito na Univates. mistephanou@uol.com.br.
} 
Na reestruturação das políticas públicas, há uma tendência de transformação do princípio organizador, em termos de políticas menos universalistas e mais focalistas. Todo esse processo justifica a necessidade de se avaliar o papel do Estado, na sua efetiva capacidade de regular a ação social através de programas e projetos sociais.

A utilização de metodologias adequadas à avaliação de políticas públicas é uma preocupação constante de órgãos públicos, e também das agências de financiamento, pois muitos projetos apresentados não asseguram sequer a sustentação dos objetivos propostos na sua implementação.

Desta forma, se a avaliação se constitui um elemento de aperfeiçoamento da gestão pública, a análise das metodologias de avaliação feita pelos órgãos financeiros internacionais, ou também chamados IFMs (Instituições Financeiras Multilaterais) torna-se relevante, principalmente por estes serem agentes que, através de associação com os governos nacionais, financiam projetos de desenvolvimento nos países membros, como é o caso do Brasil.

Instituições como Fundo Monetário Internacional (FMI), Banco Mundial $\left(\mathrm{BIRD}^{1}\right)$ e Banco Interamericano de Desenvolvimento (BID), são compreendidas como grandes instituições financeiras. No entanto, o FMI objetiva ser principalmente um fundo de estabilização monetária aos países com déficit orçamentário. Já o Banco Mundial e o BID são órgãos que se destinam a prover assistência concessional aos países em desenvolvimento e que, no Brasil, têm relevante papel no financiamento de políticas públicas. ${ }^{2}$ De forma geral, estes dois órgãos têm suas linhas gerais de propostas aos países objetivadas na redução da pobreza, na promoção da eqüidade social, na modernização do Estado, na integração regional e no desenvolvimento sustentável. Estas diretrizes foram modificadas no decorrer dos anos, pois a política dos Bancos, durante o período do regime Militar até meados da década de oitenta, estava pautada no desenvolvimento econômico, na infra-estrutura e no desenvolvimento de alguns setores produtivos estratégicos. Neste período, os chamados empréstimos de ajuste estrutural e setorial foram amplamente utili-

A filiação dos Governos Federais ao Banco Mundial está condicionada à filiação ao FMI.

2 Segundo dados oficiais das agências multilaterais, até o final de 2002 o Governo Brasileiro obteve apoio em mais de 660 projetos já financiados, perfazendo um total de aproximadamente US\$ 50 bilhões. Dados do Banco Mundial apresentam o Brasil como o segundo maior país em provimento de recursos, perdendo apenas para o México. 
zados. A imposição dessas políticas econômicas aos países criava uma contradição, visível e nada desejosa, aos pressupostos nacionalistas: a imposição de políticas econômicas, afetando a soberania do país.

A década de noventa, na linha da inserção de políticas mais focalistas, trouxe algumas mudanças bastante visíveis na política apresentada pelas agências de financiamento. Tanto o Banco Mundial quanto o Banco Interamericano desviaram seus eixos políticos para a questão da pobreza, com maior ênfase no diálogo político, e uma significativa aproximação com as Organizações não Governamentais (ONGs). Desta forma, em se tratando de agências financeiras multilaterais, que apresentam um relevante papel no financiamento no país, tanto em termos de valores quanto em termos de volume de empréstimos, as avaliações dos projetos exigidas por estes têm a preocupação em destacar a eficiência, a eficácia e o impacto junto ao público beneficiário de seus programas financiados.

Desta forma, o presente trabalho tem por objetivo fazer uma análise comparativa das metodologias de avaliação aplicadas por estes dois órgãos de fomento financeiros internacionais relevantes no país - Banco Mundial e Banco Interamericano de Desenvolvimento em projetos sociais desenvolvidos no Brasil.

Para a consecução dos objetivos propostos neste trabalho, foi realizada uma pesquisa qualitativa, pautada na análise de documentos dos órgãos financiadores internacionais, no que se refere a propostas de financiamentos para projetos sociais no país, análise das metodologias aplicadas, relatórios e publicações em geral disponibilizadas pelas agências de fomento.

Na primeira parte, será feita uma análise da trajetória das políticas sociais brasileiras, procurando identificar as mudanças ocorridas na ampliação das funções sociais no país, inseridas na agenda pública. Em seguida, será examinada a problemática das instituições públicas em apresentar políticas adequadas, introduzindo a avaliação como um instrumento necessário aos formuladores e implementadores de programas. Para isso, serão analisados os conceitos e as diferentes metodologias de avaliação existentes.

Finalmente, na última parte, será apresentada a análise comparativa das metodologias de avaliação apresentadas pelo BIRD e BID, que têm um papel relevante no país enquanto implementadores de estratégias focalizadas na 
redução da pobreza. Sendo assim, serão apresentados aqui a importância e o impacto destes compromissos junto ao Brasil, bem como a base metodológica das agências multilaterais na avaliação de projetos brasileiros, através do comparativo do ciclo de projetos, e do chamado Marco Lógico apresentado por ambos. Esta comparação é feita através de indicadores de: eficiência, efetividade e impacto dos projetos.

\section{Uma breve trajetória das políticas públicas no Brasil}

O século XX foi de ampliação das funções do Estado e do processo social, além da ampliação das funções sociais. Há uma constante dinâmica de transformações econômicas, sociais e políticas, onde as políticas sociais são parte integrante das políticas públicas, como mediadoras na relação entre Estado e sociedade.

[...] a análise das políticas sociais como parte do conjunto de políticas públicas deverá contemplar a dinâmica contraditória na qual as políticas sociais são parte intrínseca da construção coletiva e conjunta da nacionalidade, da cidadania e da institucionalidade estatal (Fleury, 1994, p. 131).

$\mathrm{Na}$ década de sessenta, a política social tinha um papel contraditório aos interesses da acumulação. Nesse período, o princípio organizador das políticas públicas ficava por conta da redistribuição. As reformas de base (agrária, urbana e administrativa) levariam o desenvolvimento social ao chamado Welfare State (Estado de Bem-Estar Social), aproximando-se este dos moldes sociais-democratas europeus.

O Welfare State teve seu surgimento nos países europeus, como conseqüência da expansão do capitalismo após a Revolução Industrial e com o movimento de um Estado Nacional que consolidasse a democracia. Ele se constituiu em uma transformação do Estado a partir de suas próprias estruturas, funções e legitimidade.

As transformações do Estado capitalista, nessa linha, acabam permitindo uma valorização da intervenção deste na economia. Os conflitos de classe, sob essa ótica, são controlados pelos mecanismos institucionais do Estado, ou seja, ficam reduzidos à sua esfera distributiva, quando este passa a atender parte das demandas sociais, permitindo assim um nível de seguridade maior, mesmo que às custas do endividamento do Estado. Essa promoção do bem- 
estar social levou a uma segurança da propriedade e lucratividade de capital, garantindo geração de renda e emprego, que indiretamente leva a uma valorização do capital. O Welfare State, portanto, define-se como um padrão de financiamento público da economia capitalista por intermédio de uma estruturação da esfera pública.

No Brasil, esse processo do Estado de Bem-estar Social inovou os campos de educação, saúde e assistência social, que começaram com ações guiadas de forma mais seletiva e fragmentada e foram superando essa fase com ações mais universalistas.

A avaliação das políticas públicas fixava-se, então, no eixo estrutural do processo e, dessa forma, deveria superar a estagnação promovendo o desenvolvimento. "A questão social como incorporação de atores sociais será subsumida numa elaboração em que a política social vai ser subsidiária dos imperativos do mercado" (Melo, 1999, p. 14).

Já no período do regime militar, havia uma tendência de submissão de políticas públicas à lógica da acumulação e de um reformismo mais conservador. Há, neste período, uma articulação com os grandes capitais internacionais e abertura de canais de financiamento, principalmente junto ao FMI e ao Banco Mundial. No governo Geisel, houve uma internalização da problemática social, de modo que a alocação de recursos para esta área tornou-se prioridade, além de haver ocorrido uma expansão das taxas de crescimento do gasto social.

A orientação do poder público, na área de políticas sociais no Brasil, foi intensificada no início da década de 1980, onde houve um processo de reorganização da sociedade civil, na busca de uma nova ordem social. Essa estratégia reformista, dentre algumas inovações, buscou redefinir o padrão regressivo de financiamento das políticas sociais, indo um pouco na contramão da reestruturação econômica e social, que acontecia em países avançados e, de certa forma, estava transferindo muito dessa responsabilidade para a sociedade civil e o mercado. A descentralização do Estado e a redemocratização foram pontos importantes na pauta de discussão. Segundo Arretche (1996), as várias concepções teóricas a respeito da crise do Estado e da descentralização de políticas públicas são vistas de forma normativa, pois estão diretamente relacionadas à descentralização das relações políticas e também à eficiência e eficácia da gestão pública. Desta forma, a autora coloca que esta descentrali- 
zação acaba protegendo as liberdades individuais das ameaças do Estado centralizador. Para um bom funcionamento destas reformas, se faz necessário, conforme Arretche (op. cit., p. 20), "[...] o fortalecimento de suas capacidades administrativas e institucionais na condução de políticas setoriais implementadas pelos governos subnacionais e do próprio processo de descentralização".

Em 1988, com a nova Constituição Brasileira, o princípio participativo ou plebiscitário foi consagrado marco de uma cultura política de oposição forjada a partir de uma forte participação da Igreja - como elemento fundamental na formulação de políticas (Souza e Lamounier, 1989). Com a atuação dos movimentos sociais, a Constituição de 88 conseguiu inserir os direitos sociais sob uma nova direção para as políticas sociais.

O governo federal passou a assumir, então, de forma prioritária, a coordenação de políticas públicas, e os municípios assumiram grande parte da execução dessas políticas. Essa postura levou a uma nova gestão das políticas públicas, onde muitas das responsabilidades e recursos, que eram somente de instância federal, foram distribuídas para governos estaduais e municipais, ainda que com muita resistência, pela forte tradição federal de, muitas vezes, tratar de forma desigual alguns estados e municípios.

Já a década de 1990 foi responsável por um período de lutas e implementação de direitos sociais assegurados na nova Constituição, tais como seguridade social, criança e adolescente, saúde e previdência social. Foi uma época de embate entre a ação de políticas públicas eficazes nas áreas de direitos conquistados e as políticas econômicas vigentes, além de todas essas experiências proporcionarem uma nova relação entre Estado e sociedade. Passados mais de vinte anos, desde o processo de redemocratização do Brasil, percebese uma reorientação da política social, como uma dimensão central do modelo das relações entre Estado, economia e sociedade. Na definição das esferas pública e privada, se redistribuem competências e recursos entre estados e outros atores sociais. Esse processo de redemocratização no Brasil levou à participação popular na chamada "coisa pública". Essa ampliação da esfera pública pode ser entendida como a "arena na qual as questões que afetam o conjunto da sociedade são expressas, debatidas e tematizadas por atores sociais [...]" (Cunha e Cunha, 2001, p. 16). 
As políticas públicas como responsabilidade do Estado envolvem conflitos de interesse entre classes sociais e agências externas. Nesse processo, é marcante o papel dos vários movimentos sociais na busca da garantia dos direitos civis políticos e sociais.

A década de noventa foi representativa do crescimento desse setor, que, no provimento de políticas públicas, estabeleceu uma parceria com o Estado que, de certa forma, transferiu parcelas de responsabilidade para as comunidades organizadas e ONGs, na busca da diminuição do impacto negativo de algumas políticas públicas. Vários analistas se referem a esse processo como uma nova esfera pública, não-estatal e democrática, que estaria diminuindo a onipotência do Estado e ampliando o espaço decisório da sociedade civil organizada. Segundo Celina Souza (2001), a expectativa que este processo de descentralização gerou, naquilo que ela chama de empowerment de governos e sociedades locais, é grande. Da mesma forma, o conceito de participação também transparece muitos significados. No caso das agências multilaterais, participação significa "[...] incorporação da voz de segmentos marginalizados ao processo decisório". A capacidade destes segmentos civis se restringe à integração, apenas no sentido de influenciar e não de decidir sobre algo. Segundo a autora, a participação como voz, e não como empowerment, é adotada no Brasil, sendo estimulada, tanto pelas recomendações de agências multilaterais, quanto "[...] por recursos externos que requerem a constituição de conselhos comunitários, para a liberação de recursos para a área social [...]" (op. cit., p. 30).

O papel que os Bancos Multilaterais desempenham são importantes no desenvolvimento e implementação de políticas públicas com enfoque na redução de pobreza. A influência de agências como o Banco Mundial e o Banco Interamericano de Desenvolvimento tem sido cada vez maior e mais efetiva nestes últimos anos.

Estas agências multilaterais buscam oferecer créditos ao país, a partir de um pressuposto, que é a condição de retomada do crescimento econômico. E essa retomada só é possível, segundo eles, a partir da realização de um ajuste fiscal e da redução da taxa de juros doméstica. Os programas de privatização do governo federal são motivados pelas agências de financiamento, o que, nesses últimos anos, têm se intensificado consideravelmente no Brasil. Isso 
tem sido motivo de fortes elogios por parte das agências financeiras multilaterais.

Mas nem sempre as imposições dos Bancos são equilibradas e suas políticas são constantemente alvo de muitas críticas. Nos anos oitenta, por exemplo, houve, segundo alguns especialistas, um desequilíbrio do setor financeiro, relacionado aos modelos impostos pelos organismos internacionais, como o Banco Mundial e FMI, que levaram a um desarranjo econômico e social do Brasil nessa época. O Banco Mundial aparece como um dos responsáveis pela desmontagem das instâncias estatais. A mudança de postura veio mais tarde, nos anos noventa, quando afirmou que estas reformas, somente, não são suficientes para abertura de novos caminhos, fazendo-se necessária uma transformação produtiva com eqüidade, redefinindo as ações de política e Estado no desenvolvimento. E hoje ainda segue grande o debate sobre as imposições de políticas das agências financeiras. A Rede Brasil, ${ }^{3}$ por exemplo, coloca o Brasil em situação de vítima do "Consenso de Washington".

O FMI, o Banco Mundial e o BID não são considerados instituições governadas pelo poder do voto dos países membros, mas como instituições divididas entre países doadores (os maiores acionistas) que regulariam as ações do Banco junto aos países tomadores de empréstimos" (Vianna Jr., 1998b, p. 6).

O que se pode ver, portanto, é que a implementação e consolidação de políticas sociais no Estado brasileiro estão inseridas dentro de um projeto nacional de reforma que o coloca para além de executor de políticas públicas. Sua função, hoje, consiste em regular, fiscalizar e incentivar políticas, ampliando as parcerias junto à iniciativa privada em atividades que não são exclusivas da competência do Estado.

Segundo Celina Souza (2001), o Brasil se caracteriza por ser um país com múltiplos centros de poder, inserido num sistema de dependência política e financeira entre a esfera governamental, não governamental e as agências multilaterais. As decisões em torno da implementação de políticas públicas, segundo a autora, são apoiadas pelos governos e sociedades locais, sem que o governo federal se transforme em um agente passivo do processo.

A Rede Brasil é uma entidade articulada por ONGs, movimento sociais e sindicatos, criada há cerca de quatro anos, que monitora a ação das Instituições Financeiras Multilaterais (IFM) no Brasil. 
Pode-se dizer que o Estado, nas políticas sociais, tem optado por programas muito seletivos e focalizados, dificultando um pouco a institucionalização das políticas a nível federal. Esse chamado "movimento contrário", segundo alguns especialistas, também é considerado uma das tendências nas políticas sociais da América Latina, além, é claro, das questões relativas à descentralização, privatização e execução de programas de base local ${ }^{4}$ e à relação Estado-sociedade.

Há ainda uma necessidade muito grande de o Estado priorizar mais as políticas sociais. A formulação de políticas públicas cria a necessidade de identificação de vários atores sociais e dos interesses que geram a implementação de determinada política. Nesse sentido, há mobilização de vários grupos da sociedade civil e do Estado para que tal processo venha a acontecer. E, nesse processo, a avaliação das políticas públicas é instrumento gerencial importante à gestão pública. A avaliação produz informações relevantes para o aprimoramento das ações governamentais. Por isso, é parte essencial do processo decisório institucional.

Dentro dessa perspectiva, o item a seguir se propõe a trabalhar as questões metodológicas referentes aos processos de avaliação de políticas, programas e projetos sociais.

\section{Metologias de avaliação em políticas públicas}

Pode-se afirmar que a avaliação em si é um ato que instrumentaliza o conhecer, o compreender, o orientar, o aperfeiçoar ações de indivíduos ou grupos. Portanto, avaliação pode ser entendida como "um processo sistemático de análise de uma atividade, fatos ou coisas que permite compreender, de forma contextualizada, todas as suas dimensões, com vistas a estimular seu aperfeiçoamento" (Belloni, 2000, p. 15).

Os interesses em realizar a avaliação de determinados programas e políticas públicas são os mais diversos, e vão muito além de simplesmente comparar os efeitos de um projeto com as metas na qual ele se propôs. De certa

4 Estes programas se constituem como criação e funcionamento das políticas sociais nas áreas de saúde, educação e assistência social através dos governos estaduais e municipais, gerando um processo de cooperação junto a União e logicamente a sociedade civil organizada. 
forma, talvez este seja realmente o objetivo, em curto prazo, da análise dos programas quando implementados.

$\mathrm{Na}$ avaliação de uma política pública, é examinada a política em si, entendida como aquelas ações de um governo com vistas ao alcance de um objetivo concreto, seus resultados e conseqüências. Assim, na análise da implementação de políticas institucionais, se faz necessário o entendimento da "missão institucional", enquanto na avaliação das políticas públicas, as instituições que implementam programas não são parte do objeto de avaliação. Nesse caso, são examinadas apenas as políticas, seus resultados e conseqüências, pois, com isso, pode-se obter contribuições da natureza e operacionalidade deste sistema político. Desta forma, a "avaliação política é a análise e elucidação do critério ou critérios que fundamentam determinada política: as razões que a tornam preferível a qualquer outra" (Figueiredo e Figueiredo, 1986, p. 2).

Além de serem elementos básicos do planejamento, a análise de políticas públicas e a avaliação de programas sociais desempenham um papel essencial nesse processo.

A análise de políticas sociais, por exemplo, possibilita o exame da engenharia institucional e dos traços constitutivos dos programas, como as formas de relação entre o setor público e o setor privado, as formas de financiamento e as modalidades de prestação de serviços (Arretche, 1999b, p. 30).

No Brasil, este processo toma maior alcance em meados da década de oitenta, inserido no processo de transição política. Como já visto, a avaliação de programas se faz necessária, a medida que as políticas sociais de urgência levassem ao combate da profunda desigualdade social presente no país.

O potencial uso de estudos de avaliação de programas e políticas, com a devida utilização de rigores teóricos metodológicos, permite que a tomada de decisões seja melhor fundamentada, além de encaminhar melhor a questão da responsabilidade e utilização qualitativa dos recursos públicos, proporcionando programas que tenham maior efetividade, eficiência e qualidade.

5 Sob essa ótica, a avaliação fica definida como o estudo que se ocupa da análise da eficiência de determinada política. 
Pode-se tratar a avaliação na perspectiva de um instrumento de aperfeiçoamento da gestão pública, pois ela não está alicerçada somente em um exercício correspondente a um cálculo de "custo benefício". Mais do que isso, ela está fixada num conjunto de valores partilhados na realidade social, que vão proporcionar e delimitar os traços constitutivos dos programas, enquanto potencializadores das necessidades essenciais da esfera social.

\section{Tipologias clássicas do estudo de avaliação}

As tendências de avaliação em políticas e programas públicos apontam para a preocupação em se avaliar se as metas foram cumpridas no decorrer do processo, e ainda se as mesmas tiveram êxito. No estudo de avaliação, existem dois focos de análise que permitem dar o subsídio necessário: o enfoque no funcionamento, e o enfoque nos resultados.

O foco no funcionamento tem, como principal meta, analisar, de forma específica, os mecanismos de funcionamento do programa. Além disto, estão também presentes, nessa análise, as etapas, os processos e as linhas causais do funcionamento do programa, permitindo, dessa forma, que haja uma intensa verificação da realidade operacional do programa, onde se poderá tomar conhecimento de como os possíveis resultados, esperados ou não, se manifestaram.

Por sua vez, o foco nos resultados está submetido à análise dos resultados que são gerados pelo programa implementado. Este tipo de estudo procura saber, de forma geral, se determinado programa implementado produziu o resultado esperado, ou não. A utilização de metodologia qualitativa, através de técnicas como entrevistas com os beneficiários do programa, é uma das referências utilizadas. Logicamente, a utilização também de recursos metodológicos focados no quantitativo é importante e sua base está fixada em dados oficiais da instituição responsável pelo programa.

$\mathrm{Na}$ perspectiva da análise do resultado, os analistas procuram trabalhar os resultados esperados ou não. No caso da análise dos dados esperados, as investigações são feitas com base naqueles resultados já previstos durante a implementação, e alcançados junto aos beneficiários. 
Já no caso da análise de dados não - esperados, o foco do estudo se volta para os fatos que surgiram no decorrer da implementação e que não estavam previstos anteriormente. Verifica-se quais os tipos de resultados que foram gerados, e como esses resultados encontrados afetam os beneficiários do programa. De certa forma, independentemente dos resultados que se queira focar, esse tipo de análise é uma importante ferramenta, tanto para os gestores, quanto para os implementadores de programas.

Ainda no foco do resultado, outro importante recurso de avaliação é o estudo de impacto, entendido como a relação entre a implementação do programa e seus resultados de forma mais ampla e complexa, pois procura captar os efeitos do programa sobre a população-alvo, sempre buscando traçar um paralelo entre a política implementada e as alterações nas condições sociais. Nos estudos de impactos, a utilização de recursos metodológicos e de pesquisa de campo é importante para a compreensão do ocorrido com os beneficiários do programa.

\section{Tipos de avaliação}

A avaliação de políticas públicas reside na adoção de diferentes técnicas na busca da formulação e implementação de políticas públicas. Na literatura da área, de forma geral, destacam-se quatro diferentes tipos decorrentes deste processo avaliativo: avaliação de Efetividade, Eficácia, Eficiência e Impacto. ${ }^{6}$

A avaliação da Efetividade se constitui no exame da relação entre a implementação e os resultados do programa sob avaliação. Ela expressa, portanto, o resultado concreto dos objetivos e metas a serem alcançados. Cohen e Franco (1993) chamam atenção para duas dimensões da avaliação de efetividade, que, quando confrontadas, permitem avaliar essa efetividade: a medida de impacto e o grau de alcance dos objetivos.

Alguns textos sobre o assunto consideram também a análise na efetividade do programa como de natureza somativa, pois se verifica até que ponto os

6 Optou-se aqui, para fins de análise, em uma divisão dos tipos de avaliação em quatro diferentes técnicas, embora algumas literaturas tratem a análise de Impacto e Efetividade com o mesmo conceito. Há algumas bibliografias que não incorporam o termo Efetividade como conceito de metodologia de avaliação, mas sim como sinônimo da palavra Impacto. 
resultados esperados foram alcançados. Esta depende muito da análise formativa, ${ }^{7}$ já que muitos programas nem sempre ultrapassam o processo de implementação. De qualquer forma, muitos estudos avaliativos dessa linha apontam para uma análise de impacto do programa junto aos beneficiários envolvidos, além de captar dados dos resultados alcançados que não eram previstos na implementação de tal programa.

A avaliação de Eficácia realiza o exame da relação entre os objetivos e instrumentos utilizados, com os resultados alcançados do programa. Sem dúvida, sua prática é muito utilizada pelas políticas públicas, já que seu custo também é mais baixo, pois ela se fundamenta na análise das metas definidas pelo programa, em relação àquelas alcançadas. A definição do sucesso ou fracasso de tal programa depende muito das informações obtidas, da questão da confiabilidade dos dados, exigindo um trabalho de campo que consiga reconstituir a implementação da política analisada. Nesse caminho, os modelos analíticos em políticas públicas apontam a eficácia na análise da produção de bens e serviços públicos que tenham, como principal meta, atingir às demandas em um determinado período de tempo. Além disto, aponta se as demandas são iguais, superiores, ou inferiores ao proposto, medindo, portanto, a eficiência de operação do projeto.

$\mathrm{Na}$ avaliação de Eficiência, por sua vez, se considera o exame da relação entre o esforço empregado na implementação e os resultados obtidos. De acordo com Arretche (op. cit.), a utilização dessa metodologia é muito necessária, à medida que há escassez de recursos públicos, contribuindo para uma certa racionalização dos gastos. Programas que priorizam o combate à pobreza, por exemplo, têm em sua raiz a tendência a essa racionalização de gastos, em que o aspecto eficiência ganha importância por trabalharem com universos populacionais muito grandes e despenderem um volume alto de recursos para a realização da ação. Ou seja, a utilização de recursos públicos, na implementação de políticas, requer um grande cuidado com a eficiência dos seus gastos.

A pesquisa formativa está interessada em analisar a etapa de implementação do programa, principalmente com relação aos aspectos que avaliam como o programa foi formado, enquanto este ainda estiver em funcionamento. Dessa forma é possível corrigir problemas, que por ventura existam, não interessando nesse caso a compressão da efetividade do programa em si. A pesquisa formativa ou somativa. Uma não exclui a outra, pelo contrário, elas dependem entre si. 
A eficiência pode ter, na realidade, duas perspectivas: quando à quantidade do produto, por exemplo, a construção de mil casas populares, já está determinada previamente, e, dessa forma, se procura racionalizar o custo; ou quando o recurso já está fixado, e se procura então encaixar os custos à quantidade do produto que se quer ter. Seu conceito está muito vinculado à análise financeira, e relacionado à noção de produtividade.

Finalmente, tem-se por avaliação de Impacto aquela que revela o desempenho de uma ação pública. Da mesma forma como foi dito anteriormente, a análise de impacto é também o exame da relação entre o esforço empregado na implementação e os resultados obtidos, mas se diferencia da efetividade por ser mais ampla e complexa. Ela capta os efeitos do programa e a sua relação com a intenção da política, e as alterações efetivas nos beneficiários. A avaliação, dessa forma, está voltada a políticas com propósitos de mudança. Nestas mudanças, pode-se considerar vários tipos de impacto, que não são, de forma alguma, excludentes um do outro. São eles:

Impactos Objetivos - alterações quantitativas na população alvo;

Impactos Subjetivos - alteram somente o "estado de espírito" dos beneficiários do programa;

Impacto Substantivo - altera de forma qualitativa as condições de vida dos beneficiários, ou seja, é importante ver se os propósitos e resultados esperados estão agindo positivamente, dentro dos princípios morais e de justiça social presente.

A análise de impacto, que depende de informações advindas da implementação do projeto, está inserida na avaliação ex-post. Sua análise pode ser feita em dois momentos: enquanto o projeto está em andamento e depois de finalizado. Sua análise, embora eficiente e mais ampla, não consegue o controle total de todas as variáveis ambientais que atuam no ciclo total da implementação. 


\section{Análise comparativa das metologias de avaliação utilizadas pelo BIRD e BID}

\section{O Grupo Banco Mundial}

O BIRD foi criado em 1945 nos EUA, com uma política de ação voltada ao provimento de concessões financeiras a países em situação de risco, em situação de emergência humanitária, na reconstrução de países pós-conflito e desastres naturais. Seu enfoque principal está voltado à promoção do progresso econômico e social aos países necessitados, principalmente no que diz respeito à redução da pobreza e à promoção do desenvolvimento sustentável.

O BIRD conta hoje com 183 países membros, entre os quais o Brasil. O Banco é considerado a maior fonte de assistência ao desenvolvimento, com cerca de US\$30 bilhões anuais ${ }^{8}$ em empréstimos a países, sendo só no Brasil um total de US\$ 6 bilhões. A política de investimentos do BIRD está voltada para a promoção de um crescimento econômico sustentável. Mas, segundo eles, o desafio vai muito além, requerendo um equilíbrio entre programas econômicos e sociais, que devem ser trabalhados em parceria com todas as esferas da sociedade (governo, banco, sociedade civil, e setor privado). O reconhecimento de um projeto para o BIRD só faz sentido se o mesmo contribuir para o desenvolvimento, além da elaboração a partir de um amplo leque de perspectivas setoriais e temáticas.

No Brasil, o BIRD vem atuando desde 1949, com um apoio em mais de trezentas e oitenta operações de crédito, totalizando uma soma de US\$ 33 bilhões. No país, o representante maior do Banco é o Ministro da Fazenda, intitulado Governador do Brasil no BIRD, que possui um capital de 1,67\% do Banco.

No início da década de oitenta, o BIRD começou com uma modalidade de empréstimos, denominados empréstimos de ajuste estrutural, que, mais tarde, se tornaram empréstimos de ajuste setorial. Essa nova modalidade foi tomada como resposta à crise econômica pela qual o Brasil e outros países da América Latina estavam passando. Estava impregnada, aí, a noção de que o

8 Dado extraído do Ministério das Relações Exteriores do Brasil. <www.mre.gov.br> em maio de 2002. 
desenvolvimento no país seria possível, através do crescimento econômico orientado, na competição junto ao mercado internacional. Os ajustes estruturais foram concedidos aos países através de quatro pontos básicos: realização de uma política comercial de preços; revisão da política de investimentos públicos; reorientação da política orçamentária; reformas institucionais com garantia de maior eficácia ao setor público.

A partir dos anos noventa, na Reforma do Estado no Brasil, se preconizava a focalização do Estado no atendimento das necessidades sociais básicas, através de uma redução da sua área de atuação por intermédio de três mecanismos chave: privatização, publicização ${ }^{9}$ e terceirização. Ao poder executivo, ainda cabia a formulação, acompanhamento e implementação de políticas públicas. Esse contexto, já um pouco tardio com relação aos outros países da América Latina, foi também resultado das políticas de ajuste do Banco Mundial e dos Planos de Estabilização do FMI.

Para que a assistência ao Brasil seja efetuada, o BIRD possui um documento chamado de Estratégia de Assistência ao País (Country Assistance Strategy-CAS), ${ }^{10}$ que traça as estratégias para financiamento e assistência, a países como o Brasil. Neste documento, dentre as estratégias de assistência apresentadas, estão itens que envolvem desde o diagnóstico das questões chaves entre o diálogo do governo e do Banco no traço das políticas públicas, até aquelas relacionadas com a perspectiva do projeto, avaliação dos riscos, implementação e indicadores de referência.

No Brasil, segundo o BIRD, a questão de políticas sociais na área de pobreza e desigualdade continuam sendo as mais importantes e os maiores desafios na área do desenvolvimento em longo prazo. Além disso, o BIRD considera importante seu apoio em ensino básico, saúde pública (prestação de serviços), projetos agrários, prestação de serviços urbanos (infra-estrutura social e física), proteção social e meio ambiente, ${ }^{11}$ entre outras.

9 Entende-se publicização como o movimento de transformação dos órgãos estatais em "entidades públicas não-estatais", ou seja, aquelas de direito privado, sem fins lucrativos.

10 Disponível: <www.worldbank.org/br>.

11 O BIRD considera a gestão ambiental como peça chave do desenvolvimento do Brasil, através de uma administração mais eficaz dos recursos naturais e dos problemas que a poluição urbana traz. 
No ano de 2000, o Banco Mundial discutiu uma estratégia de colaboração com o governo do Brasil para os próximos anos. A Estratégia considera que o Brasil teve avanços significativos nas reformas econômicas e sociais, tornando-se uma economia mais moderna. Nessa idéia, encontram-se as privatizações e melhorias na educação. Os avanços consolidaram reformas que efetivamente levaram a uma redução da pobreza e a um processo de crescimento sustentável. Mas o principal objetivo da Estratégia de Assistência ao Brasil é a redução da pobreza. No sentido dessa redução, há algumas metas para atingir:

ajuste fiscal sustentável;

retomada do crescimento;

efetividade do desenvolvimento;

administração dos ativos ambientais.

\section{O Grupo do Banco Interamericano de Desenvolvimento}

O Banco Interamericano de Desenvolvimento (BID), é uma instituição financeira criada em 1959, cuja sede está em Washington D.C., e se constitui na principal fonte de financiamento multilateral para América Latina e Caribe. O Banco surgiu no contexto da Guerra Fria e promoveu a redefinição das políticas estruturais aos países periféricos. A partir da década de sessenta, com o aval do Banco Mundial, o BID introduziu as Américas nos seus planos, sendo que a participação mais intensificada ocorreu mesmo nas décadas de oitenta e noventa, particularmente na América Latina e Caribe.

O BID possui capital próprio, além de recursos obtidos no mercado financeiro e de outros fundos de administração, no sentido do desenvolvimento econômico, institucional e social dos países que o compõem, e hoje conta com quarenta e seis membros. ${ }^{12}$

12 Os 46 membros se constituem: 26 países mutuários da América Latina e do Caribe; 20 não mutuários, entre eles Estados Unidos, Japão, Canadá, 16 países europeus e Israel. 
Os empréstimos do BID entre os anos de 1961 e 2000 alcançaram US\$106 bilhões para projetos. ${ }^{13}$ Os empréstimos foram aplicados em vários benefícios sociais e infra-estrutura aos países membros, que vão desde a expansão de escolas e hospitais, passando por obras de infra-estrutura em transporte e comunicação, até a execução de projetos ambientais com vistas a promoção sustentável e social. A sua estratégia de empréstimos e financiamentos está alicerçada em três indicadores chave: a promoção da eqüidade social; redução da pobreza e crescimento sustentável do ponto de vista ambiental.

Para isso, o Banco ressalta a importância de se promover a implementação de reformas institucionais que objetivamente aumentem a eficácia, e ampliem o alcance junto à população necessitada, além de assistir em políticas e projetos de inclusão social. O controle dos projetos acontece através do Escritório de Avaliação e Supervisão, que está subordinado à Diretoria Executiva, é independente da administração do Banco e avalia estratégias, políticas e o impacto dos projetos.

O Brasil é membro do BID desde a sua criação em 1959, e possui um capital ordinário de $11,07 \%$. A autoridade máxima do BID no Brasil é o Ministro do Planejamento e Orçamento, que faz parte da Assembléia de Governadores, tendo, como representantes, ministros da economia ou finanças, ou ainda o presidente do Banco Central. As ações e projetos do BID no país estão concentrados no setor de reforma, modernização do Estado e redução da pobreza.

O Brasil, principal cliente do BID, já recebeu, em termos de financiamento, desde o início da trajetória do Banco, 20,7\% do total emprestado aos países membros do grupo. A soma do montante, em termos de créditos que o país recebeu, chega a US\$22,1 bilhões num total de 280 projetos.

A atuação do BID no Brasil, entre o início dos anos sessenta e o final da década de oitenta, foi intensa em áreas de infra-estrutura (transporte, indústria, mineração). Os investimentos na área social, principalmente em termos de educação, construção de casas populares e saneamento básico também foram relevantes. A partir dos últimos anos, foram inseridas novas diretrizes

13 Em torno de $80 \%$ dos empréstimos que o Banco oferece, são provenientes de fundos adquiridos dos mercados financeiros mundiais. Fonte: BID 
do Banco em virtude também das mudanças estruturais do país. Essas orientações estão definidas em um documento de assistência ao país, chamado Documento de País (Brasil). ${ }^{14}$ A partir desse documento, o BID define suas metas em cima de três áreas de mudança da política de desenvolvimento do país: a abertura econômica; as medidas para diminuir a inflação e a modificação do regime de câmbio. De acordo com o Banco, as reformas estruturais que promoveram as privatizações, a integração regional e uma maior responsabilidade fiscal, tornaram o país mais moderno e em pleno processo de desenvolvimento.

Nessa linha de prioridades, o BID quer implementar uma agenda social integrada, que colabore mais com a cooperação entre os vários setores. $\mathrm{O}$ investimento social, com ênfase na redução da pobreza, além de uma melhor infra-estrutura na prestação de serviços básicos, são estratégias importantes para o desenvolvimento do país.

\section{Ciclo de projetos}

Na fase de elaboração e avaliação dos projetos, as agências multilaterais possuem coordenações em secretarias especiais que se envolvem com os assuntos relativos aos projetos. No Brasil, os financiamentos do BIRD são coordenados pela Secretaria de Assuntos Internacionais do Ministério do Planejamento, Orçamento e Gestão (SEAIN-MPO). É através da SEAIN que os órgãos públicos elaboram uma carta consulta à COFIEX - Comissão de Financiamentos Externos. Depois, o BIRD é consultado, e, em seguida, depois de aprovados, os projetos são desenvolvidos em parceria. ${ }^{15} \mathrm{O}$ BIRD conta ainda com o OED - Operation Evaluation Department na linha de avaliação dos projetos. A OED é um departamento de avaliação das operações do Banco que é independente, e tem vínculo direto com os diretores executivos. Fornece as informações e a metodologia para avaliação dos resultados de projetos financiados pelo BIRD, sempre buscando experiências e identificando as lições aprendidas. O quadro abaixo apresenta os ciclos do BIRD.

14 Esse documento segue parcialmente a metodologia do CAS - Banco Mundial.

15 A SEAIN coordena tanto financiamentos quanto empréstimos do BIRD ao Brasil. 


\begin{tabular}{|c|c|c|}
\hline \multicolumn{3}{|c|}{$\begin{array}{c}\text { Quadro 1 } \\
\text { Ciclo de Projetos BIRD }\end{array}$} \\
\hline Fases do Projeto & Atribuições & Responsabilidade \\
\hline Identificação & $\begin{array}{ll}\checkmark & \text { Apresentação das } \\
& \text { estratégias segundo } \\
& \text { o CAS no Brasil; } \\
\checkmark & \text { proposta do mutuá- } \\
& \text { rio; } \\
\checkmark & \text { análise econômica } \\
& \text { do BIRD ao proje- } \\
& \text { to; } \\
\checkmark & \text { projetos anteriores. }\end{array}$ & BIRD e mutuário \\
\hline Preparação & $\begin{array}{l}\text { Elaboração de vários } \\
\text { estudos técnicos, - } \\
\text { sociais, e econômicos }\end{array}$ & $\begin{array}{c}\text { Mutuário com a } \\
\text { assistência do BIRD }\end{array}$ \\
\hline Avaliação & $\begin{array}{l}\text { Benefícios do projeto } \\
\text { ao país e os riscos de } \\
\text { sua implementação }\end{array}$ & BIRD \\
\hline $\begin{array}{c}\text { Negociação } \\
\text { e apresentação }\end{array}$ & $\begin{array}{l}\text { Definição do acordo de } \\
\text { empréstimo, com o } \\
\text { planejamento das } \\
\text { operações* }\end{array}$ & BIRD e mutuário \\
\hline $\begin{array}{l}\text { Implementação } \\
\text { e Supervisão }\end{array}$ & $\begin{array}{l}\text { A implementação é de } \\
\text { responsabilidade do } \\
\text { mutuário, enquanto a } \\
\text { supervisão é exclusiva } \\
\text { do BIRD. }\end{array}$ & $\begin{array}{l}\text { Mutuário e BIRD } \\
\text { respectivamente }\end{array}$ \\
\hline Avaliação ex-post & $\begin{array}{l}\text { Avaliação de todos } \\
\text { aspectos do projeto, e } \\
\text { sua relação custo/ } \\
\text { benefício }\end{array}$ & BIRD e mutuário \\
\hline
\end{tabular}

* Após a aprovação, é publicado o Documento de Avaliação do Projeto.

Da mesma forma, o BID, para efetuar a etapa da avaliação dos projetos, conta com o OVE - Escritório de Avaliação e Supervisão, que está diretamente vinculado à Diretoria Executiva, sendo independente da administração do Banco. Além de avaliar estratégias e políticas dentro dos objetivos iniciais 
propostos, são feitas também avaliações de impacto dos projetos.O quadro abaixo apresenta os ciclos do BID.

\section{Quadro 2}

\section{Ciclo de Projetos BID}

\begin{tabular}{|c|c|c|}
\hline Fases do Projeto & Atribuições & Responsabilidade \\
\hline Identificação & $\begin{array}{l}\checkmark \quad \text { apresentação do pedido de } \\
\text { financiamento do governo } \\
\text { ao banco; } \\
\checkmark \quad \text { estratégias de preparação } \\
\text { do projeto. }\end{array}$ & BID e mutuário \\
\hline Preparação & $\begin{array}{ll}\checkmark & \text { definir o projeto; } \\
\checkmark & \text { estabelecer seus compo- } \\
& \text { nentes; } \\
\checkmark & \text { determinar custos. }\end{array}$ & Mutuário \\
\hline Análise & $\begin{array}{l}\text { benefícios do projeto e } \\
\text { aplicabilidade financeira. }\end{array}$ & BID \\
\hline $\begin{array}{l}\text { Negociação e } \\
\text { aprovação }\end{array}$ & $\begin{array}{c}\text { definição do acordo de } \\
\text { empréstimo. }\end{array}$ & BID e mutuário \\
\hline $\begin{array}{l}\text { Execução e } \\
\text { Supervisão }\end{array}$ & $\begin{array}{l}\text { execução do projeto e supervi- } \\
\text { são do banco para assegurar a } \\
\text { eficácia deste. }\end{array}$ & $\begin{array}{l}\text { Mutuário e BID } \\
\text { respectivamente }\end{array}$ \\
\hline
\end{tabular}

Percebe-se uma proximidade muito grande no ciclo de projeto dos Bancos, apesar do BID adotar um indicador a menos que o BIRD no quadro. Este corresponde à avaliação ex-post, que, conforme já apresentado no segundo capítulo, avalia quais aspectos e informações aparecem no processo de implementação e acabam influenciando no projeto. Mesmo não indicado, ele está subentendido como parte do ciclo de projetos do BID, na área de execução e supervisão, pois a avaliação ex-post também está presente durante o transcorrer do projeto, quando se busca graus de eficiência e eficácia do mesmo. Além do que, está presente também, nos projetos do Banco, principalmente quando este define, no Documento Brasil, a análise do impacto dos programas que, como se sabe, faz parte da análise dos projetos com enfoque nos resultados, sempre em conformidade com as diretrizes estratégicas do desenvolvimento social no país presentes nesse documento. 


\section{Marco lógico}

Dentre as ferramentas formais de avaliação do ciclo de projetos, ainda na fase que corresponde à análise ex-ante, aparece o chamado Marco Lógico, ${ }^{16}$ que é considerado um instrumento muito importante nas fases de elaboração, análise e gerenciamento de projetos. Ele oferece uma visão lógica do projeto nas suas relações de causa e efeito, e é utilizado especialmente pelas organizações de cooperação internacional, como é o caso do BIRD e do BID. Sua análise está baseada numa matriz de quatro linhas para quatro colunas, conforme quadro a seguir:

\section{Quadro 3}

Estrutura do Marco Lógico

\begin{tabular}{|l|l|l|l|}
\hline $\begin{array}{l}\text { Descrição dos } \\
\text { objetivos }\end{array}$ & $\begin{array}{l}\text { Indicadores } \\
\text { Verificáveis }\end{array}$ & $\begin{array}{l}\text { Meios de } \\
\text { Verificação }\end{array}$ & $\begin{array}{l}\text { Fatores de risco } \\
\text { (Premissas) }\end{array}$ \\
\hline $\begin{array}{l}\text { Finalidade } \\
\text { (Objetivo Geral) }\end{array}$ & $\begin{array}{l}\text { Indicadores de } \\
\text { Impacto do } \\
\text { projeto (tempo, } \\
\text { qualidade, } \\
\text { quantidade. }\end{array}$ & $\begin{array}{l}\text { Fontes de dados, } \\
\text { e informações, } \\
\text { material publica- } \\
\text { do para indicar o } \\
\text { Impacto. }\end{array}$ & $\begin{array}{l}\text { Indica as } \\
\text { condições para a } \\
\text { sustentabilidade } \\
\text { do projeto. }\end{array}$ \\
\hline $\begin{array}{l}\text { Propósito } \\
\text { (Objetivo } \\
\text { específico) }\end{array}$ & $\begin{array}{l}\text { Indicadores de } \\
\text { Efetividade do } \\
\text { projeto em rela- } \\
\text { ção ao objetivo } \\
\text { específico. }\end{array}$ & $\begin{array}{l}\text { Fontes de dados, } \\
\text { e informações, } \\
\text { material publica- } \\
\text { do para indicar a } \\
\text { Efetividade. }\end{array}$ & $\begin{array}{l}\text { Os fatores exter- } \\
\text { nos que podem } \\
\text { condicionar ao } \\
\text { alcance do } \\
\text { projeto. }\end{array}$ \\
\hline $\begin{array}{l}\text { Resultados: } \\
\text { situações, } \\
\text { serviços e } \\
\text { produtos que } \\
\text { produzidos } \\
\text { pelo projeto }\end{array}$ & $\begin{array}{l}\text { Indicadores de } \\
\text { Desempenho } \\
\text { onde se verifica } \\
\text { em que medida os } \\
\text { resultados foram } \\
\text { alcançados. }\end{array}$ & $\begin{array}{l}\text { Fontes de dados, } \\
\text { e informações, } \\
\text { inspeções, para } \\
\text { indicar o } \\
\text { desempenho. }\end{array}$ & $\begin{array}{l}\text { Fatores externos } \\
\text { que condicionam } \\
\text { o alcance dos } \\
\text { objetivos. }\end{array}$ \\
\hline
\end{tabular}

16 Criado nos EUA, no começo dos anos setenta, ele analisa um projeto como um conjunto de hipóteses e de relações de causa e efeito, explicitando as relações entre as Atividades, os Resultados, os Objetivos do Projeto e o Objetivo Geral, além de cobrar a explicitação dos fatores de risco do projeto. 


\begin{tabular}{|c|c|c|c|}
\hline $\begin{array}{l}\text { Atividades: } \\
\text { tarefas que o } \\
\text { executor deve } \\
\text { cumprir para } \\
\text { alcançar os } \\
\text { resultados }\end{array}$ & $\begin{array}{l}\text { Indicadores Ope- } \\
\text { racionais: } \\
\text { realização das } \\
\text { atividades, } \\
\text { cronograma e } \\
\text { recursos. }\end{array}$ & $\begin{array}{l}\text { Registro contábil } \\
\text { da unidade } \\
\text { executora e o } \\
\text { cronograma. }\end{array}$ & $\begin{array}{l}\text { Fatores externos } \\
\text { fora do controle } \\
\text { do projeto que } \\
\text { condicionam o } \\
\text { alcance dos } \\
\text { resultados. }\end{array}$ \\
\hline
\end{tabular}

* Adaptado de Armani, 2000.

Certamente, esse enfoque melhora a qualidade de desempenho dos projetos e programas, auxilia na planificação de projetos mais detalhados e oferece um suporte muito bom no seguimento da avaliação.

Dentre as vantagens do enfoque, tanto o BIRD quanto o BID destacam a linguagem que este possui. Por ser mais uniforme, facilita a comunicação e reduz as ambigüidades, que, muitas vezes, são responsáveis pelas más interpretações que acabam colocando em risco o andamento de um projeto.

Na segunda coluna da matriz apresentada, aparecem os Indicadores que correspondem a um instrumento de medição que indica as mudanças na realidade social que se está buscando. A presença deles também é muito vantajosa, pois objetivam transformar os conceitos em parâmetros mensuráveis, ou seja, operacionalizam conceitos. No caso específico do Marco Lógico, as agências chamam a atenção para a construção de indicadores que sejam adequados ao projeto e, no caso do Brasil, que sejam indicadores necessários à estratégia do desenvolvimento social. O Marco Lógico também leva vantagem na planificação de projetos mais detalhados, conseguindo também que a parte interessada intervenha no processo de planejamento e avaliação. ${ }^{17}$

Por outro lado, há algumas limitações nesse enfoque, pois, como está mais voltado aos resultados, efeitos e impactos, ele deixa de verificar a compreensão do porquê das mudanças ocorridas. O BID demonstra que sua aplicação, única e exclusiva, pode se converter em um instrumento estático de análise, pois não revela as novas condições que o projeto proporciona. Apesar de ter um custo relativamente baixo, seria, portanto, importante complemen-

17 Segundo Armani (2000, p. 36), “O Marco Lógico é recomendável, pois se baseia no método científico de pesquisa social, estruturando os projetos sobre uma cadeia de hipóteses acerca das relações de causas e efeito envolvidas no enfrentamento da problemática em questão". 
tar o Marco Lógico com experiências de avaliação que enfatizem os aprendizados do processo, para, assim, se ter uma análise avaliativa mais rica em informações.

\section{Operações de Avaliação BIRD/BID: O Impacto como uma ferramenta importante para os projetos de redução da pobreza no Brasil}

Os Bancos multilaterais procedem a suas operações, como já se afirmou anteriormente, dentro das estratégias propostas em cada país mutuário. No caso do Brasil, as metas estratégicas na área de redução da pobreza e promoção do desenvolvimento sustentável são trabalhadas por ambos, e estão orientadas ao desenvolvimento social.

Conseqüentemente, no que se refere a avaliações, tanto o BIRD quanto o BID estão muito preocupados com o desempenho, e levam suas estratégias voltadas ao resultado dos projetos, além de terem uma preocupação especial com a eficácia das instituições que realizam os projetos. A ferramenta da avaliação é considerada muito importante, e prioridade na contribuição de uma forma mais eficaz e eficiente de assegurar o sucesso de um projeto e o conseqüente impacto deste, no avanço do desenvolvimento.

Para o BIRD, as operações do OED - Operation Evaluation Department são importantes, pois fornecem a base para informações das metodologias de avaliação do Banco. As avaliações do OED promovem, segundo eles, o accountability. Assim, os projetos que são selecionados para avaliação de desempenhos são reunidos com o propósito de reduzir custos e aumentar o impacto. São realizadas avaliações do auxílio do país, em conformidade com a estratégia do CAS.

Segundo a OED, a avaliação é feita seguindo alguns critérios de desempenho que são considerados importantes: o resultado, a sustentabilidade, o impacto institucional de desenvolvimento, desempenho do BIRD e mutuário. Fica claro em seus princípios que a avaliação é feita em termos do confronto dos resultados com os objetivos indicados no projeto respeitando as políticas temáticas do país em questão. 
No que a OED considera como processo de avaliação dos resultados, são levados em conta os seguintes critérios:

importância dos objetivos, em relação as prioridades de cada país, no caso o Brasil;

eficácia, considerada aqui "a extensão a que os objetivos desenvolvidos (ou que se espera ser) e o que foi conseguido";

eficiência, "extensão a que os objetivos (ou se esperam ser) foi conseguida sem usar mais recursos do que necessário".

Esta avaliação dos efeitos identifica o que, de certa forma, repercute de forma positiva e/ou negativa, na instituição, no desenvolvimento social do país e no desenvolvimento do projeto. Sua aplicação, segundo o Banco, orienta projetos e políticas e contribui para o desenvolvimento de projetos futuros. Proporciona, segundo o BIRD, um equilíbrio entre a investigação através de métodos quantitativos e qualitativos. Mas, de certa forma, cai no inconveniente de ser uma avaliação mais custosa e lenta, pois ela pode durar anos, entre o projeto em andamento e o projeto já concluído.

No que se refere a impacto, o BIRD preocupa-se em como o projeto melhora o país, ou região, com a utilização dos seus recursos. Ou seja, como se dá o sucesso do projeto na promoção de mudanças significativas para a população beneficiária. A avaliação de impacto, segundo eles, permite examinar as conseqüências previstas e não previstas aos beneficiários e se elas são positivas ou negativas. Algumas questões são importantes serem respondidas nesse caso, segundo o Banco:

Como o projeto afetou os beneficiários?

Algum benefício foi resultado direto do projeto?

O desenho do programa poderia ter se modificado para melhorar a repercussão do projeto?

Justificam-se os custos?

Necessariamente, para se buscar respostas a essas perguntas, é necessário mobilizar esforços para que se utilize instrumentos de coleta de dados apropriados, buscando sempre a qualidade das informações a que se quer buscar. A utilização destes instrumentos e sua elaboração devem ser feitas pelo Ban- 
co com participação de analistas que representem o país do onde o projeto foi executado.

As avaliações de Impacto que a OED realiza ao BIRD revisam os projetos desenvolvidos no período que compreende entre cinco e oito anos após a última parcela de empréstimo.

Na mesma linha, o BID, junto com o OVE tem procurado assegurar projetos que levem ao desempenho desejado no impacto do desenvolvimento humano. Assim, para que a avaliação traga aprendizado a todos os envolvidos no projeto, autoridades do país, técnicos do Banco, setor público, enfim a toda equipe, torna-se necessário avaliar os sucessos e fracassos, aplicados ao longo do ciclo do projeto. Sua importância ao Banco consiste em melhorar a capacidade de avaliação e contribuir para o aumento da efetividade dos projetos, principalmente no que diz respeito à capacidade de gestão dos governos e à aplicação de políticas públicas mais eficazes. No quadro abaixo, seguem as diretrizes mais importantes que o BID sustenta na avaliação de projetos, como uma ferramenta de melhor desempenho das políticas.

\section{Quadro 4}

\section{PONTOS IMPORTANTES}

O desempenho do Banco e dos mutuários com relação a execução dos projetos pode melhorar desenvolvendo melhor a capacidade de avaliação;

A avaliação pode contribuir para melhorar o impacto do desenvolvimento dos projetos se utilizado como instrumento de aprendizagem;

A avaliação reduz os riscos ocorridos na execução dos projetos;

A avaliação serve como respaldo a reforma do setor público;

O BID utiliza diversas estratégias para desenvolver a capacidade de avaliação nos países;

O BID utiliza a avaliação para promover o aprendizado institucional. 
Em análises feitas aos documentos referentes as metodologias de avaliação, presentes no EVO - Avaliação do Marco Lógico, o BID define duas categorias de Impacto, que estão presentes em diferentes momentos, que é importante ressaltar:

Impacto ou efeito - em suas definições, é considerado como as conseqüências planejadas, e/ou também não previstas do projeto.

Avaliação de Impacto - É a avaliação ex-post que se realiza, geralmente, cinco anos depois de concluído o projeto, e se define enquanto fim em si, ou seja, no propósito dos indicadores presentes no Marco Lógico, assim como também em seus efeitos imprevistos.

Os dois tipos de avaliação são igualmente importantes, e de acordo com a discussão do segundo apresentada no segundo capítulo, estão inseridos na mesma matriz de avaliação ex-post. Já que o impacto de um projeto em si pode ser verificável, durante e depois de concluído o projeto.

O BID, por sua vez, em sua matriz de avaliação, separa esses dois impactos em dois momentos: O impacto e efeitos estão presentes no que ele chama de Avaliação Operativa do tipo ex-post, onde são feitos os ajustes, análises de eficácia, eficiência, e efeitos e impactos. São realizadas também as negociações do projeto no que se refere a uma possível mudança deste, caso seja necessário.

Já a Avaliação de Impacto está presente na avaliação ex-post, onde se produz avaliações, estratégias e políticas dos programas executados, contribuindo para verificação dos impactos tecnológicos, institucionais, econômicos, políticos, socioculturais e ambientais, junto aos beneficiários do programa. Dentro da mesma idéia, discutida no capítulo anterior, de Impactos objetivos, Impactos subjetivos e substantivos. O quadro abaixo mostra exatamente as duas matrizes de avaliação de impacto apresentadas pelo BID: 


\section{Quadro 5}

Matriz de avaliação Operativa e Ex-post

\begin{tabular}{|c|c|c|}
\hline Matriz & Questões & Análise \\
\hline Avaliação & Continuidade do projeto & Indicadores \\
\hline \multirow{3}{*}{ Operativa } & Efetividade & Fonte de dados \\
\hline & Eficiência & Método de Coleta de Dados \\
\hline & Efeitos e Impactos & \\
\hline \multirow{7}{*}{$\begin{array}{l}\text { Avaliação } \\
\text { ex-post }\end{array}$} & Impactos tecnológicos & Indicadores \\
\hline & Impactos institucionais & Fonte de dados \\
\hline & Impactos econômicos & Método de Coleta de Dados \\
\hline & Impactos políticos & \\
\hline & Impactos sociais & \\
\hline & Impactos ambientais & \\
\hline & Outros & \\
\hline
\end{tabular}

Nessa busca de uma avaliação centrada no impacto e nos resultados, com base em produtos concretos de desempenho, fica evidente que as linhas de avaliação, que as agências multilaterais estão buscando, concentra-se cada vez mais em fortalecer a capacidade de avaliação e de efetividade de seus projetos financiados. E essa avaliação só é possível através do trabalho conjunto entre agências, governos e sociedade.

A interlocução com a sociedade civil, dos discursos e práticas das agências multilaterais de desenvolvimento têm sido destacadas na política de ação dos Bancos, e isso tem auxiliado para que esse diálogo seja constante. Por outro lado, se há esse discurso de invocação da sociedade civil para o contexto das políticas das agências multilaterais, há também tensões que são visíveis sobre esse discurso. Na abordagem do BID, a sociedade civil está diretamente ligada à questão do processo de modernização do Estado, que, por outro lado, no BIRD é incorporada mais para uma lógica antiestatista, onde a participação da sociedade civil se configura como o mais importante procedimento, pela qual o desenvolvimento social e o avanço democrático sejam efetivados.

As agências multilaterais têm, na avaliação das políticas implementadas, uma contribuição para o aumento eficaz da qualidade dos projetos e ações 
financiadas aos países membros em todas as etapas do ciclo. A análise feita, antes, durante e depois de concluído o projeto, é importante em seu conjunto, pois identifica os problemas, podendo corrigi-los, antes que os efeitos sejam contrários. E, segundo o BIRD, a partir do ano 2000 houve um avanço considerável na tarefa de avaliação dos projetos.

Isso é importante, em termos de Brasil, pois, de acordo com os estudos de implementação de programas no país, a agenda social está num processo mais progressivo de programas sociais. Alguns estudos realizados pelo BID mostram que a eficácia e eficiência nas intervenções de políticas públicas de cunho mais preventivo têm sido uma resposta positiva aos problemas sociais. Isso em muito tem haver com a avaliação constante de programas, que, dessa forma, pode gerar a implementação de projetos eficientes, antes que os problemas sociais sejam agravados.

\section{Considerações finais}

A discussão apresentada neste trabalho promoveu uma análise sobre o propósito da avaliação de políticas públicas no marco das ações das agências multilaterais no Brasil.

A trajetória das políticas públicas no Brasil mostra como ocorreram mudanças amplas e significativas do papel do Estado junto ao processo de implementação dessas políticas. A reforma do Estado no Brasil, a partir da transição do regime militar, passou por transformações que foram no caminho da democratização no país. As ações do Estado passaram, então, por uma tendência de racionalização e uma certa reorientação com os gastos públicos e com projetos mais focalizados no combate à pobreza.

A avaliação de políticas, dessa forma, contribui para aumentar a racionalidade dos gestores na tomada de decisões conseguindo, dentro do possível, solucionar os problemas e otimizar a utilização dos recursos. Não se pode pensar na execução de um programa sem a utilização da avaliação, que se revela um instrumento importante na orientação de resultados mais efetivos, e um marco para a realização de projetos futuros.

O desenvolvimento da capacidade de avaliação torna-se, cada vez mais, uma prioridade das agências multilaterais, sendo elas também responsáveis, 
em parte, pela garantia de uma boa gestão do governo federal, já que fica muito claro nos documentos estratégicos das agências de fomento a prioridade em financiamentos a projetos que estabelecem impactos significativos e que, conseqüentemente, tragam reformas necessárias ao bom desempenho do setor público.

De certa forma, tanto o BIRD quanto o BID impõem que o Brasil e todos os tomadores de empréstimos se esforcem nessa reforma do setor público. Há uma necessidade de reformas estruturais do Estado porque, segundo as estratégias de desenvolvimento impostas pelos Bancos, é somente através desse processo que se pode garantir a consecução de programas públicos com maior eficácia e efetividade.

A todo modo, este comportamento que conduz a determinadas imposições dos Bancos aos países membros é alvo de muitas críticas, principalmente quanto da capacidade do Estado em cumprir certas tarefas fundamentais e básicas na redução da pobreza. A formação de uma base estável para o desenvolvimento do mercado e da organização civil; manutenção de políticas econômicas estáveis; investimento em serviços sociais básicos; política ambiental são requisitos importantes, mas que impõem problemas na agenda do Estado. Há falta de recursos para garantir uma burocracia de qualidade com melhor gestão. Ainda mais que existe um embate constante com os padrões clientelistas e corporativos das políticas públicas no País.

Fica claro que os esforços empregados pelos Bancos seguem o mesmo caminho, que é o de redução da pobreza no Brasil com a retomada de seu desenvolvimento econômico. Conseqüentemente, na análise comparativa de suas metodologias, se percebe a tendência de se avaliar os impactos dos projetos financiados. Este impacto, entendido como a relação entre a implementação de um programa e seus resultados, se configura o ponto principal da análise dos projetos. A ênfase nos resultados é importante para as agências multilaterais, pois é a base para a verificação das exigências que estas têm para com os países membros.

Es evidente la importancia que reviste la calidad de los sistemas de los países para la medición y control de los resultados, en relación con la exigencia que tenemos ante nosotros. Esto impone una prima a nuestro respaldo a la creación de capacidad de administración del sector público, estadístico y sistemas de control y evaluación, que son importantes en sí mismos para el sustento de la responsabi- 
lidad de los países frente a sus ciudadanos, y de los acuerdos y convenios con donantes en función de los resultados.

De certa forma, há questionamentos quanto à aplicabilidade de se realizar avaliação de políticas na área social. Então, quando se fala em gasto público, sempre se volta a projetos que precisam ter uma base técnica sólida para que a sua implementação tenha sucesso, e que na maioria das vezes não acontece. E, muito por conta disso, os órgãos financiadores internacionais estão exigindo cada vez mais a avaliação dos projetos financiados por eles nos países membros. Dentro da linha do Marco Lógico, se verifica a possibilidade de estabelecer maior grau de eficiência de um projeto ainda em fase de implementação, já que é neste momento que se desenha as estratégias e objetivos a serem aplicados. Na seqüência, os olhares das agências se voltam para a avaliação dos resultados, e por isso os estudos de impacto ganham notoriedade pelos Bancos, apesar de serem mais caros e custosos, já que em cada etapa do processo surgirão problemas para implementá-lo. Mas essas dificuldades só reforçam a importância de se contar com uma análise planejada e uma avaliação que aconteça desde a etapa inicial do projeto.

Faz-se necessária, também, a promoção de uma maior transparência no acesso às informações para acordar com as propostas apresentadas pelos Bancos de garantir maior participação da sociedade civil e maior clareza das ações do Estado. Existe já um esforço dos Bancos em promover esta estratégia de divulgação das informações, mas ainda se faz necessário uma política de divulgação mais democrática, compartilhando os princípios do direito público da sociedade em ter acesso à concepção e implementação dos projetos.

Certamente a análise comparativa proposta neste trabalho leva a uma reflexão sobre as metodologias de avaliação e a importância que estas têm na execução de políticas públicas mais eficientes. Contudo, a vigilância crítica que devemos ter em relação às instituições multilaterais vai muito além da análise de seu papel enquanto promotor do desenvolvimento de políticas sociais. As agências multilaterais, reconhecendo este aspecto, estão investindo na avaliação como forma de garantir projetos de impacto junto ao público

18 Declaração pública feita em 20 de março de 2002, em Monterrey pelos presidentes dos Bancos Munltilaterais. Extraído da página do Banco Mundial, <www.bancomundial.org.br> em outubro de 2002 . 
beneficiário. Cabe à sociedade civil, cada vez mais inserida no diálogo, junto às agências e intermediadas pelas ONGs, estar no front desta vigilância, para que a avaliação dos projetos seja mais criteriosa e consiga salvaguardar seu fim último: redução da pobreza e promoção da eqüidade social.

\section{Referências}

ARRETCHE, Marta T. S. Políticas sociais no Brasil: descentralização em um Estado federativo. Revista Brasileira Ciencias Sociais, v. 14, n. 40, p.111-141, jun. 1999a.

—. Estudo sobre avaliação. In: RICCO, Elisabeth Mello (org.). Avaliação de políticas sociais: uma questão em debate. São Paulo: Cortez, 1999b.

_. Mitos da Descentralização: Mais democracia e eficiência nas políticas públicas? Revista Brasileira de Ciências Sociais, n. 31, jun. 1996.

ARMANI, Domingos. Como elaborar projetos? Guia prático para elaboração e gestão de projetos sociais. Porto Alegre: Tomo Editorial, 2000.

Banco Interamericano de Desarrollo-Bid. Oficina de Evaluación. Evaluación: una herramienta de gestión para mejorar el desempeño de los proyetos (Marco Lógico). Washington: DC, 1997. Internet: www.iadb.org/cont/evo/SPBook.htm, capturado em: agosto de 2002.

julho de 2002.

Relatório Anual BID. Washington DC. Internet: <www.iadb.org>, capturado em: outubro de 2002.

Banco Mundial - BIRD. Estratégia de Assistência ao pais/CAS - relatório n. 20160/BR. Internet: <www.worldbank.org/br>, capturado em: outubro de 2002.

- Anual Report on Operations Evaluation. Washington DC. Internet: <www.worldbank.org/oed>, capturado em: outubro de 2002.

. Seguimiento y Evaluación: instrumentos, métodos y enfoques. Washington DC. Internet: <www.worldbank.org/oed>, capturado em: outubro de 2002.

BAKER, Judy L. (2002). Evaluación del impacto de los proyectos de desarrollo en la pobreza - Manual para profesionales. Banco Mundial, Washington DC, 2000. Internet: <www.worldbank.org>, capturado em: dezembro de 2002.

BELLONI, Isaura. Metodologia de avaliação em políticas públicas: uma experiência em educação profissional. São Paulo: Cortez, 2000. (Coleção Questões da Nossa Época, v. 75)

CARVALHO, Alysson (org.) [et.al.]. Políticas públicas. Belo Horizonte: UFMG/PROEX, 2002. 
CASTRO, Maria H. G. Avaliação de políticas e programas sociais. Caderno de Pesquisa NEPP/Unicamp, São Paulo, n. 12, out. 1989.

COHEN, Ernesto; FRANCO, Rolando. Avaliação de projetos sociais. Petrópolis: Vozes, 1993.

COSTA, Valeriano Mendes Ferreira. O novo enfoque do Banco Mundial sobre o Estado. Lua Nova - Revista de Cultura Política, São Paulo, n. 44, p. 5-26, 1998.

DRAIBE, Sonia. Rumos e metamorfose: um estudo sobre a constituição do Estado e as alternativas da industrialização no Brasil, 1930/1960. Rio de Janeiro: Paz e Terra, 1985.

FIGUEIREDO, Marcos F.; FIGUEIREDO, Argelina M. Avaliação política e avaliação de políticas: um quadro de referência teórica. Textos IDESP, São Paulo, n. 15, 1986.

FLEURY, Sônia. Estado sem cidadãos: seguridade social na América Latina. Rio de Janeiro: Fiocruz, 1994.

HABERMAS, Jurgen. A nova intransparência: a crise do estado de bem-estar social e o esgotamento das energias utópicas. Novos Estudos, São Paulo, n. 18, p. 103-114, 1987.

LINDER, S. H.; PETERS, B. G. Relativism, contigency and the definition of sucess in implementation research. Polyce Studies Review, Arizona State University, v. 7, n. 1.

MELO, Marcus A. As sete vidas da agenda pública brasileira. In: RICCO, Elisabeth Mello (org.). Avaliação de políticas sociais: uma questão em debate. São Paulo: Cortez, 1999.

NEPP/Unicamp. Modelo de avaliação de programas sociais prioritários - Relatório Final. Campinas, jul. 1999, mimeografado.

OFFE, Claus. A democracia partidária competitiva e o Welfare State keynesiano: fatores de estabilidade e desorganização. In: Problemas estruturais do estado capitalista. Rio de Janeiro: Tempo Brasileiro, 1984a.

RAICHELIS, Raquel. Esfera pública e Conselhos de Assistência Social: caminhos da construção democrática. São Paulo: Cortez, 1998.

SILVA, Pedro; MELO, Marcus A. O processo de implementação de políticas públicas no Brasil: características e determinantes da avaliação de programas e projetos. São Paulo: Caderno de Pesquisa NEPP/Unicamp, n. 48, 2000.

SOTTOLI, Suzana. La política social en América Latina bajo el signo de la economia de mercado y la democracia. In: Revista Europea de Estudios Latinoamericanos y del Caribe, Amsterdam, n. 68, p. 3-22, 2000.

SPOSATI, A.; FALCÃO, M. C. do; FLEURY, S. M. Os direitos (dos desassistidos) sociais. 3. ed. São Paulo: Cortez, 1995. 
SOUZA, Amaury; LAMOUNIER, Bolívar. A feitura de nova constituição: um rexame da cultura política brasileira. Planejamento e Políticas Públicas, n. 2, 1989.

SOUZA, Celina. Descentralização, relações intergovernamentais e empowerment dos governos e sociedades locais em contextos de desigualdades. In: Revista Humanas, Porto Alegre: UFRGS, v. 16, n. 1/2, p.17-33, 2001.

VIANA, Ana Luiza. Abordagens metodológicas em políticas públicas. São Paulo: Caderno de Pesquisa Unicamp, n. 5, out. 1989.

VIANA Jr.; Aurélio; BARROS, Flávia (org.). Banco Mundial: participação, transparência e responsabilização: a experiência brasileira com o Painel de Inspeção. Rede Brasil: Brasília, 2001.

VIANA JR. A estratégia dos bancos multilaterais para o Brasil - Análise crítica a documentos inéditos. Brasília, 1998a. Internet: www.rbrasil.org.br, capturado em: outubro, 2002.

. Rede Brasil promove debates sobre as instituições financeiras multilaterais. In: Informativo INESC. Brasília, n. 86, p. 6, ago. 1998 b.

WEISS, Carol H. Evaluation research: methods of assesing program effectiveness. Englewood Cliffs, NJ: Prentice-Hall, 1972.

\section{Páginas oficiais consultadas:}

Avança Brasil - Governo Federal: <www.abrasil.gov.br>

Banco Interamericano de Desenvolvimento: $<$ www.iadb.org.br $>$

Banco Mundial: <www.worldbank.org/br $>$

Comissão Econômica para América Latina: $<$ www.imf.org $>$

Estudo dos Eixos Nacionais de Integração e Desenvolvimento: <www.eixos.gov.br>

Fundo Monetário Internacional: <www.imf.org $>$

Ministério do Planejamento Orçamento e Gestão: <www.planejamento.gov.br >

Ministério das Relações Internacionais: <www.mre.gov.br $>$

Operation Evaluation Department /BIRD: <www.oecd.org $>$

Rede Brasil: <www.rbrasil.org.br>

Texto recebido em janeiro de 2005 e aprovado em março de 2005. 